\title{
СОСТОЯНИЕ НА СЕГОДНЯШНИЙ ДЕНЬ, ПРОБЛЕМЫ И ПЕРСПЕКТИВЫ РАЗВИТИЯ ИНФРАСТРУКТУРЫ «УМНОЙ МЕДИЦИНЫ» В ЦИФРОВОЙ ЭКОНОМИКЕ
}

\author{
(C) 2020 Ануркин Н. М. \\ студент-магистрант \\ Самарский государственный экономический университет, Россия, Самара \\ E-mail: anurkin-94@mail.ru \\ (c) 2020 Лошкарев А. В. \\ кандидат юридических наук \\ Самарский государственный экономический университет, Россия, Самара \\ E-mail:2482337@mail.ru
}

В статье рассмотрены основные проблемы и перспективы развития инфраструктуры «умной медицины» в цифровой экономике. Сделан вывод о необходимости более активного вмешательства государства в данные процессы, путем стимулирования субъектов экономической деятельности, разработки и внедрения соответствующих технологий с целью создания полноценной инфраструктуры (в первую очередь - соответствующих баз данных) для развития «умной медицины» в Российской Федерации.

Ключевые слова: умная медицина, телемедицина, электронные медицинские карты, цифровая медицина, система ОМС.

Технологическая революция, связанная с глобальной информатизацией и повсеместным развитием онлайн-сервисов, приводит к увеличению доли цифровой экономики. Как отмечает И.В. Сударушкина, цифровую экономику следует понимать как результат трансформационных эффектов новых технологий общего назначения в области информации и коммуникации, которые влияют на все секторы экономики и социальной деятельности [1]. Очевидно, что столь серьезные «тектонические» процессы не могли не задеть также и медицину, представляющую собой важную сферу экономики и социальной деятельности. Поэтому, на сегодняшний день, медицина представляет собой сферу, в которой наблюдается динамический рост цифровизации. Исследование инноваций в здравоохранении Американского колледжа кардиологии (American College of Cardiology) показали широкий спектр направлений в развитии цифрового здравоохранения, а так же многочисленные взаимосвязи между изучаемыми методами и способами в управлении большими данными, яркими примерами таких направлений можно назвать: роботы в здравоохранении (самым известным из которых является хирургическая система да Винчи (da Vinci Surgical System, США), наноботы (микроскопические роботы близкие по масшта- бу к нанометру), 3-D печать (одно из направлений которого является биопечать тканей и органов), портативные ультразвуковые устройства, имплантируемые датчики (сенсоры) и т.д. [2].

Одним из ведущих направлений цифровизации медицины является, так называемая, «умная медицина» в которой важным аспектом социальной эффективности в здравоохранении является доступность и преемственность медицинской помощи, а так же удовлетворенность пациентов ее качеством. К основным направлениям «умной медицины» можно отнести телемедицинские консультации, мобильные приложения и медицинские гаджеты. Как отмечает Г.И.Курчеева, в широком смысле под «умной медициной» понимаем интеллектуальное здравоохранение, которое использует новейшие мобильные и цифровые достижения в области электронного здравоохранения (eHealth) и мобильного здравоохранения (mHealth), что стимулирует развитие умных и подключенных медицинских девайсов, обеспечивающих постоянное отслеживание показателей пациентов вне стен медицинских учреждений и, соответственно, предупреждение болезней [3]. Благодаря «умной медицине» возможно обеспечение как можно более ранней первичной диагностики заболеваний, а также постоянный контроль со- 
стояния пациента, что особенно важно как для выявления, так и для лечения целого ряда хронических заболеваний.

Цифровая инфраструктура опирается, прежде всего, на обработанные данные. Очевидно, что чем больше данных о пациенте введено в систему цифровой медицины и обработано, тем лучшие результаты для больного возможно ожидать. Именно цифровизация данных и создание единой системы медицинских данных о пациенте является важной предпосылкой для дальнейшего развития «умной» медицины. Как показывает зарубежный опыт, данные системы успешно применяются в ряде государств: так, например, в Эстонии система единых цифровых медицинских карт была внедрена еще в 2008 году, а в Швеции охват электронной медицинской карты достиг 100\% еще в 2012 году [4].

Наличие единой медицинской базы данных с надлежащим наполнением и уровнем правовой защиты является обязательной предпосылкой для формирования системы «умной» медицины. В научной среде нет сомнений в том, что именно электронные медицинские карты являются базовой инфраструктурой для развития инновационной медицины [5]. Тем не менее, на сегодняшний день, такая система в Российской Федерации находится в процессе имплементации.

Так, в соответствии с данными исследования, которые провела компания «Медицинские информационные исследования» в октябре 2019 г. (опрошено более 4000 врачей), только 4\% российских врачей полностью перешли на электронные медицинские карты пациента [6]. В лучшем случае медицинские специалисты ведут электронные медицинские карты параллельно с бумажными, что полностью нивелирует суть электронных медицинских карт.

Помимо объективных причин, связанных с недостаточным уровнем подготовки медицинских специалистов к осуществлению операций по заполнению и ведению электронных медицинских карт, корень проблемы лежит также и в субъективном неприятии части пациентов и медицинских работников электронных систем. В то же время пандемия коронавируса и растущее количество онлайн-сервисов приводят к тому, что отношение к электронным услугам постепенно меняется в лучшую сторону, что обуславливает более широкое распространение электронных сервисов.
Тем не менее, по мнению специалистов, эволюционный сценарий имплементации электронных медицинских карт займет, как минимум, несколько лет, что приведет к нарастанию технологической отсталости Российской Федерации от других государств, которые вышли на более высокий уровень цифровизации медицинских услуг. Исходя из вышеизложенного, целесообразным представляется внесение изменений в действующее законодательство, регламентирующее, что денежные средства, уплаченные за услуги, предоставленные по системе ОМС, компенсируются исключительно в том случае, если ведется электронная медицинская карта больного. Такая норма позволит произвести действительно массовую цифровизацию данных о больных и станет важным шагом на пути к внедрению системы «умной» медицины.

Наиболее перспективным направлением «умной» медицины на сегодняшний день является телемедицина. Как отмечает М.Д. Прилуков, на сегодняшний день большинство экспертов сходится во мнении относительно положительного влияния телемедицины [7]. Такие сервисы позволяют, с одной стороны, оптимизировать оказание помощи больным, уменьшив соответствующие транспортные расходы, а с другой стороны - оказать высококвалифицированную помощь людям, находящимся за сотни и тысячи километров от высокоспециализированной медицинской клиники.

Несмотря на то обстоятельство, что в Российской Федерации действует нормативноправовое регулирование, которое предусматривает телеконсультации, только $2 \%$ жителей Москвы пользуются данной услугой, несмотря на то обстоятельство, что более трех четвертей пациентов потенциально готовы получать данные услуги в онлайн-режиме [8]. Вышеизложенное свидетельствует о провале коммуникационной работы соответствующих служб, а также об отсутствии удобных интерфейсов для осуществления телемедицины: поиск надлежащего интерфейса, фактически, становится совместной работой пациента и врача, что, безусловно, негативно влияет как на качество, так и на позитивное восприятие таких услуг пациентами. Одним из выходов из такой ситуации может стать создание единого, унифицированного медицинского приложения, в рамках которого всеми врачами РФ, подключенными к системе ОМС, будут оказываться соответствующие услуги. 
Отдельно следует отметить вопрос реализации функций искусственного интеллекта, который уже сегодня является важным диагностическим помощником при определении целого ряда заболеваний. Как отмечает М.И. Муслимов, уже сегодня точность при диагностике опухолей по радиологическим изображениям превышает 90\% [9]. При этом очевидно, что точность указанных систем возрастает при использовании bigdata - большого массива информации, сотен тысяч соответствующих изображений. В то же время очевидно, что использование медицинской информации в таких объемах должно гарантировать анонимизацию такой информации и соблюдение медицинской тайны. Исходя из вышеизложенного, представляется необходимым внесение изменения в действующее законодательство относительно определения поряд- ка анонимизации медицинской информации, содержащей врачебную тайну, и ее использования системами искусственного интеллекта.

Таким образом, следует констатировать, что современное состояние с имплементацией системы «умной» медицины во врачебную практику в Российской Федерации находится на довольно низком уровне. Несмотря на наличие законодательной базы, объективные технологические и субъективные факторы мешают быстрому применению таких технологий в столь консервативной сфере как медицина. Исходя из вышеизложенного, ускорение развития данной сферы прямо связано с проактивной позицией государства, которое должно не только создавать необходимую нормативную базу, но и стимулировать субъекты экономической деятельности, а так же активно внедрять указанные технологии.

\section{Библиографический список}

1. Сударушкина Ирина Владимировна, Стефанова Наталья Александровна Цифровая экономика // АНИ: экономика и управление. 2017. № 1 (18). URL: https://cyberleninka.ru/article/n/tsifrovaya-ekonomika (дата обращения: 26.09.2020).

2. S. Bhavnani. 2017 Roadmap for Innovation - ACC Health Policy Statement on Healthcare Transformation in the Era of Digital Health, Big Data, and Precision Health / S. Bhavnani, S. S. Hayek, R.S Druz, H. Krumholz // Journal of the American College of Cardiology - 2017. - № 70 (21),- C. 2696-2718

3. Курчеева Галина Ивановна, Клочков Георгий Алексадрович Особенности, направления и принципы формирования «умной медицины» в цифровой экономике // Научно-технические ведомости Санкт-Петербургского государственного политехнического университета. Экономические науки. 2018. № 1. URL: https:// cyberleninka.ru/article/n/osobennosti-napravleniya-i-printsipy-formirovaniya-umnoy-meditsiny-v-tsifrovoyekonomike (дата обращения: 26.09.2020).

4. Коданева С. И. Цифровые технологии в здравоохранении: зарубежный опыт // Россия: тенденции и перспективы развития. 2020. № 15-1. URL: https://cyberleninka.ru/article/n/tsifrovye-tehnologii-v-zdravoohraneniizarubezhnyy-opyt (дата обращения: 26.09.2020).

5. Кухтичев Антон Алексеевич Электронная медицинская карта как основа сервисов цифровой медицины информационной системы «ЦифроМед» // Вестник НГУ. Серия: Информационные технологии. 2016. № 1. URL: https://cyberleninka.ru/article/n/elektronnaya-meditsinskaya-karta-kak-osnova-servisov-tsifrovoy-meditsinyinformatsionnoy-sistemy-tsifromed (дата обращения: 26.09.2020).

6. Электронная медицинская карта [Электронный ресурс].- Режим доступа: http://zdrav.expert/index.php/\% D0\%A1\%D1\%82\%D0\%B0\%D1\%82\%D1\%8C\%D1\%8F:\%D0\%AD\%D0\%BB\%D0\%B5\%D0\%BA\%D1\%82\%D1\%80\%D0 \%BE\%D0\%BD\%D0\%BD\%D1\%8B\%D0\%B5_\%D0\%BC\%D0\%B5\%D0\%B4\%D0\%B8\%D1\%86\%D0\%B8\%D0\%BD\%D1\% 81\%D0\%BA\%D0\%B8\%D0\%B5_\%0\%BA\%D0\%B0\%D1\%80\%D1\%82\%D1\%8B_(\%D0\%AD\%D0\%9C\%D0\%9A, свободный.

7. Прилуков М.Д. проблемы правового регулирования телемедицины. российский и международный опыт // Вестник ННГУ. 2018. № 6. URL: https://cyberleninka.ru/article/n/problemy-pravovogo-regulirovaniyatelemeditsiny-rossiyskiy-i-mezhdunarodnyy-opyt (дата обращения: 26.09.2020).

8. КозловаА.С., Новиков А.Г. Направления развития цифровой экономики: телемедицина // Экономика, управление, финансы: материалы VIII Междунар. науч. конф. (г. Краснодар, февраль 2018 г.). - Краснодар:

9. Муслимов Муслим Ильясович Цифровое здравоохранение - как фактор революционных преобразований в отрасли // Современные проблемы здравоохранения и медицинской статистики. 2018. № 3. URL: https:// cyberleninka.ru/article/n/tsifrovoe-zdravoohranenie-kak-faktor-revolyutsionnyh-preobrazovaniy-v-otrasli (дата обращения: 26.09.2020). 